\title{
GRUPO DO NAP: ATENDIMENTO AMBULATORIAL AO CLIENTE EM USO DE MEDICAÇÃO DEPÓSITO - UMA AÇÃO DIFERENCIADA DE CUIDAR EM PSIQUIATRIA
}

\author{
LAN GROUP: AMBULATORY ASSISTANCE TO THE CLIENT IN USE OF LONG ACTING \\ NEUROLEPTICS - A DIFFERENT ACTION FOR CARE IN PSYCHIATRY \\ GRUPO DO NAP: ATENCIÓN POR CONSULTA EXTERNA AL CLIENTE QUE UTILIZA MEDICACIÓN \\ DEPÓSITO - UNA ACCIÓN DIFERENCIADA DE CUIDAR EN PSIQUIATRÍA
}

\author{
Maria Angélica de Almeida Peres', Nébia Maria Almeida de Figueiredo²
}

\begin{abstract}
${ }^{1}$ Enfermeira Residente em Enfermagem Psiquiátrica e Saúde Mental-UNI-RIO/Marinha do Brasil.
${ }^{2}$ Professora Titular do Depto.de Enfermagem Fundamental da Escola de Enfermagem Alfredo Pinto.
\end{abstract}

\section{PALAVRAS-CHAVE:}

Enfermagem psiquiátrica.

Ambulatório hospitalar.

Psicoterapia de grupo.
RESUMO: O objeto de estudo é o trabalho de grupo realizado com clientes psicóticos em tratamento ambulatorial, que fazem uso de Neuroléptico de Ação Prolongada (NAP). Trata-se de uma pesquisa de natureza qualitativa cujo objetivo geral é identificar quais são as conseqüências do trabalho realizado pelo grupo operativo junto aos clientes que usam NAP. Os dados foram produzidos a partir de 08 entrevistas semi-estruturadas com pacientes que freqüentaram o grupo durante 6 meses. Como resultados, verificou-se que o cliente psiquiátrico é capaz de participar de tal atividade e a partir dela estabelecer vínculos afetivos de fundamental importância para que participe do tratamento com maior entendimento do mesmo.

\section{KEYWORDS:}

Psychiatric nursing. Outpatient clinics hospital.

Psychotherapy of group.

\begin{abstract}
The object of this study is the operative group work with psychotic clients in ambulatory treatment which are using Long-Acting Neuroleptics (LANs). This is a qualitative research and its general objective is to identify the main results of the work, that is realized by the group with the clients that are using LANs. The data were collected through semi-structured interviews with 08 patients that participated in the operative group for six months. As results, we observed that the psychiatric client is able to participate of this kind of activity and to make affective ties, that are very important to have a better understanding about the treatment.
\end{abstract}

PALABRAS CLAVE:

Enfermería psiquiátrica. Servicio ambulatorio en hospital. Psicoterapia de grupo.
RESUMEN: El objeto de estudio es el trabajo de grupo realizado com clientes psicóticos en tratamiento por consultorio externo que utilizan Neuroleptico de Acción Prolongada (NAP). Se trata de una investigación de naturaleza cualitativa, cujo objetivo general es identificar cuales son las consecuencias del trabajo realizado por el grupo, junto a los clientes que usan NAP. Los datos fueron producitos a partir de 08 entrevistas semi-estructuradas, com clientes que frecuentaron el grupo durante 06 meses. Como resultados, se verificó que el cliente psiquiátrico es capaz de participar de tal actividad y a partir de ella establecer vínculos afectivos de fundamental importancia para que participe del tratamiento, com major entendimiento del mismo.
Endereço:

Nébia Maria Almeida de Figueiredo

Rua Visconde de Abaeté, 63/209

20551-080 - Vila Isabel, Rio de Janeiro, RJ

E-mail: aguaonda@uol.com.br
Artigo original: Pesquisa

Recebido em: 15 de maio de 2004

Aprovação final: 10 de outubro de 2004

Texto Contexto Enferm 2004 Out-Dez; 13(4):535-42. 


\section{INTRODUÇÃO}

Um dos principais desafios no processo de atendimento ao cliente psiquiátrico ambulatorial constitui-se na oferta de serviços que despertem nele o interesse de participar do seu tratamento. Este estudo desenvolveu-se como uma nova proposta de atenção ao cliente não hospitalizado, partindo de uma alternativa assistencial onde se pode observar as modificações ocorridas nos clientes nela inseridos, tendo como objeto de análise o trabalho de grupo realizado com clientes psicóticos em tratamento ambulatorial, que fazem uso de Neuroléptico de Ação Prolongada (NAP).

A atual dedicação da assistência psiquiátrica em conduzir o cuidado para o âmbito extra-hospitalar, atuando nos centros de atenção diária, centros de atenção psicossocial e ambulatórios, é resultado da consciência dos malefícios que o isolamento nosocomial pode produzir no doente.

Atuando como enfermeira residente de uma Unidade de Saúde Mental militar, pude observar que muitos clientes vão ao ambulatório para a administração do NAP, e a maioria deles só freqüenta a consulta médica periódica, não estando inseridos em nenhuma outra atividade terapêutica, sendo comum o abandono do tratamento.

A reforma psiquiátrica procurou reformular $\mathrm{o}$ tratamento psiquiátrico, tendo, na ampliação de ambulatórios, uma forma de reorganizar as atividades terapêuticas fora do âmbito hospitalar. Assim, a Unidade de Saúde Mental estudada nos estimulou a criar projetos que ampliassem a condição de ser humano de cada cliente, a fim de colocá-lo na gerência de sua própria vida, ou em parte dela, dependendo da situação.

Partindo dessa condição, elaboramos uma nova forma de atendimento ambulatorial aos clientes em uso de medicação depósito, através de grupo operativo, considerando que os ambulatórios, "funcionando em consultas espaçadas e repetindo burocraticamente prescrições medicamentosas enraizadas pelo hábito, não alteram o ciclo internação-alta-internação e acaba por representar um outro circuito de cronificação da clientela, marcado pela indução a farmacodependência"1:80.

Quando não se pode evitar a internação, é de fundamental importância a continuidade do tratamento do doente em casa após a alta hospitalar, no entanto, sabe-se que, apesar de ser o ideal, nem sempre isso é possível porque, muitas vezes, a família não é capaz de receber o cliente psiquiátrico em casa, sendo necessário, em algumas situações, a internação. A enferma- gem psiquiátrica pode e deve propor em sua prática, atividades para transformar as condições oferecidas ao cliente após a alta hospitalar, visando diminuir as dificuldades na sua readaptação ao meio social e, conseqüentemente, o número de internações.

Sendo assim, despertamos para um atendimento em grupo que visasse a modificação significativa da estrutura ambulatorial vigente e oportunizar a participação efetiva dos clientes e seus familiares no processo terapêutico, uma vez que substituir ou complementar o atendimento médico tradicional por um espaço coletivo de escuta e acolhimento produz resultados clínicos favoráveis e inequívocos ${ }^{2}$.

Diante de uma reflexão sobre o processo de reabilitação psicossocial e o que pode resultar da técnica de grupo operativo, é possível observarmos que se trata de um momento de "fala" e de "escuta", no qual surgem manifestações do cotidiano, trocas afetivas, relações de poder e de trocas sociais. O processo de reconstrução de um indivíduo com sofrimento psíquico é também uma questão de permitir a ele ser cidadão e possuir contratualidade, que é a capacidade de efetuar trocas afetivas e matérias, nos três principais âmbitos sociais: casa, trabalho e rede social ${ }^{3}$.

A necessidade de transformação das instituições psiquiátricas nos leva a repensar a forma como está sendo estabelecido o tratamento ambulatorial após a alta hospitalar, a fim de proporcionar ao cliente uma postura melhor de convivência na sociedade. Para tanto, é fundamental que o paciente recupere sua liberdade de ir e vir, de falar, de escolher, para que ele construa uma postura própria de relação com o mundo 4 .

Sabe-se que fatores externos interferem na vida do doente mental e são desencadeantes de novas crises, e que, a assistência a esse doente deve ir além da consulta médica/medicação, proporcionando a ele outras abordagens de acompanhamento e tratamento. Dessa forma, faz-se necessário um investimento assistencial para mantê-lo no tratamento ambulatorial.

A proposta do Grupo do NAP é a de buscar indícios de recuperação no cliente dito "crônico", mostrando que a sua participação em atividades semanais em ambulatório é possível, que daí surgem trocas afetivas e sociais e que a atuação terapêutica surge de acordo como são trabalhadas as relações no grupo, quando o cliente passa de mero espectador a agente formador de toda a sua terapêutica, com possibilidade de opinar e conduzir, juntamente com um profissional, o seu tratamento da melhor forma possível.

O empobrecimento da qualidade de vida, rela- 
cionado à doença psiquiátrica, leva-nos a pensar em acreditar que este cliente poderá conseguir um novo perfil social se, uma equipe com enfoque multidisciplinar investir em novas abordagens "acolhedoras" como os grupos operativos com abordagem simplificada fomentadoras de mudanças internas. Com isso, foram elaborados os seguintes objetivos para o estudo: identificar e descrever as conseqüências do trabalho realizado pelo grupo em clientes que usam NAP; analisar estas conseqüências como efeitos terapêuticos nos clientes que usam NAP, propondo atividades a serem implementadas.

\section{METODOLOGIA}

Trata-se de um estudo com abordagem qualitativa, envolvendo a obtenção de dados descritivos, obtidos no contexto do pesquisador com a situação estudada, fazendo com que o mesmo, necessite de maior conhecimento e domínio do assunto, enfatizando mais o processo do que o produto, retratando a perspectiva dos participantes ${ }^{5}$.

Os sujeitos foram os clientes em uso de medicação depósito que freqüentaram o grupo do NAP no período de janeiro a julho do ano 2000, o que representou um total de 07 grupos, uma vez que é uma atividade mensal. Optamos em desenvolver o trabalho junto aos clientes que fazem uso de NAP, por ser procedente de diferentes abordagens terapêuticas e estar sempre em busca de melhoria no seu tratamento. Muitas vezes repetem-se as internações, ocorre o abandono familiar e conseqüente abandono do tratamento.

As informações foram colhidas através de entrevista e observação participante, tendo como instrumentos de coleta de dados um roteiro de entrevista semi-estruturado e um livro de registro. Foram realizadas 08 entrevistas individuais com participantes do grupo de NAP, tendo sido gravadas em fita cassete e transcritas para posterior análise, mantendo o anonimato dos entrevistados por meio de atribuições de nomes fictícios. Tais depoimentos foram concedidos com prévia autorização, na forma de Consentimento Livre e Esclarecido, segundo a Resolução 196/96, do Conselho Nacional de Saúde 6 . As anotações de campo foram feitas por um integrante da equipe, não sendo necessariamente sempre o mesmo. Os registros tiveram enfoque maior nos conteúdos temáticos dos grupos e no comportamento do cliente nele.

A análise das informações que foram transformadas em dados partiu do resultado das entrevistas e dos registros de campo, seguindo o método de seleção e categorização dos achados, para posterior discussão e fundamentação de acordo com a bibliografia segundo as temáticas: saúde mental, enfermagem psiquiátrica, equipe multiprofissional, psicofarmacologia e grupoterapia.

\section{GRUPO DO NAP/ PROPOSTA TERAPÊU- TICA}

O Neuroléptico de Ação Prolongada (NAP) ou medicação depósito é utilizado em clientes que apresentam sintomas psicóticos, a fim de evitá-los. Algumas vantagens são atribuídas ao seu uso: por ser uma droga injetável, nos dá a certeza da dose administrada, o que difere da medicação oral, que muitas vezes é desprezada pelo cliente, e pelo seu efeito de longa duração, possibilitando intervalos de administração que variam entre 15 e 30 dias.

Devido ao efeito de longa duração do NAP, os clientes que dele fazem uso, vêm ao ambulatório, apenas no dia da sua administração, que geralmente coincide com o dia da consulta médica.

Os clientes que fazem uso de medicação depósito são aqueles com longa duração de atendimento psiquiátrico que, em sua maioria, são procedentes de várias internações. Assim sendo, após a alta hospitalar, a instalação do tratamento com NAP, resumido apenas na consulta médica, poderá surtir efeito temporário, pois o êxito do tratamento dependerá de uma equipe profissional integrada que se dedique a dar reforço e continuidade as orientações dadas, para que realmente se diminua o número de reinternações.

Optamos pela técnica operativa de grupo devido sua característica estar centrada na tarefa: ou seja, privilegia a tarefa grupal, o caminho para a obtenção de seus objetivos ${ }^{7}$. São consideradas como vantagens do trabalho de grupo: possibilidade da pessoa expressar-se e sentir o que experimenta como preocupante ou traumático; ajudar a desenvolver sua capacidade de discernimento sobre conflitos de pertinência e não pertinência; possibilidade de contínua produtividade terapêutica global, independente das resistências individuais; vivenciar relações interpessoais em ambiente protegido de grupo; rapidez de resultados, pela oportunidade que as pessoas têm de experimentar formas de solucionar seus próprios problemas ${ }^{8}$.

O Grupo do NAP, assim denominado pela equipe, acontece uma vez por mês no ambulatório de uma Unidade de Saúde Mental, tem a duração de cin- 
qüenta minutos e conta com a participação de usuários de medicação depósito e de uma equipe formada por duas enfermeiras e uma assistente social, que utilizam a técnica de grupo operativo para desenvolverem o trabalho.

Os clientes chegam ao grupo, através de um convite impresso que lhes é entregue no dia em que ele vem ao ambulatório para a administração do NAP, através de outros clientes que freqüentam o grupo, ou através de convite verbal feito por algum profissional da instituição.

O grupo tem tema livre, e geralmente, os clientes abordam temas referentes à sua situação perante a vida, falam sobre suas dúvidas e receios quanto aos amplos aspectos da doença mental, uso da medicação e efeitos colaterais, entre outros. Dessa forma, surge a demanda para que sejam feitas as orientações pertinentes pela equipe que sempre procura valorizar a importância do tratamento e estimular a participação do cliente no mesmo.

A técnica de grupo operativo escolhida é utilizada a fim de promover uma utilização mais funcional dos recursos internos latentes do indivíduo. O cliente psiquiátrico em geral apresenta uma série de dificuldades quanto ao relacionamento interpessoal, trocas afetivas, dificuldades de aceitação da doença e limitações causadas por ela.

A equipe procura promover interação entre todos os participantes, a fim de estabelecer relações de troca e ajuda. "O atendimento em grupo funciona como facilitador das comunicações entre os usuários, especialmente aqueles que detêm o mesmo código lingüístico e cultural. Durante o grupo diferentes vivências e experiências de manejo de situações de crise aparecem nos discursos e podem influenciar ou levar a uma mudança de decisão ou de atitude dos outros usuários que formam o grupo" 9:58.

Dessa forma, o grupo funciona como um espaço onde se exercita, entre outras, a capacidade de ouvir e ser ouvido, o que permite "[...] a relativização do mal estar de cada um ao escutar o outro, o que permite ao usuário formular uma demanda mais adequada ao seu estado" 10:24, abrindo espaço para a equipe realizar esclarecimentos que possivelmente irão interferir na forma de lidar com a doença psiquiátrica.

Marcado para iniciar às quatorze horas, é comum que alguns clientes cheguem na parte da manhã para consulta médica, administração do NAP ou apenas para almoçar na instituição. Esses clientes manifestam-se ansiosos quanto ao grupo, indagando aos fun- cionários que encontram, ou aos responsáveis pelo grupo, se haverá o mesmo. Esse momento de espera do início da atividade também funciona como um momento de trocas, pois os clientes vão almoçar juntos, ficam juntos enquanto aguardam, alguns passeiam pelo jardim da instituição de mãos dadas ou ficam na sala de espera do ambulatório conversando com os que lá aguardam atendimento.

Uma outra atividade que surgiu do grupo foi a comemoração dos aniversários do mês, que acontece após o término da atividade. $\mathrm{Na}$ reunião anterior levanta-se quem serão os aniversariantes do próximo mês e então se combina o que cada um poderá trazer para a comemoração. Veremos adiante que durante a entrevista, a maioria dos clientes refere gostar muito desse momento de comemoração, alguns trazem presentes para os aniversariantes o que torna esse momento muito importante no processo terapêutico.

\section{Reconhecimento e valorização do tratamento}

O grupo do NAP deve ser entendido como um dispositivo de cuidado ambulatorial, para estimular a participação do cliente psiquiátrico no tratamento, aumentar sua capacidade de produção, estimular o autocuidado, melhorar sua convivência em familia e sociedade.

Dentro da proposta de grupo operativo, decorrente da reestruturação da assistência psiquiátrica, analisamos os dados coletados buscando evidenciar as conseqüências desse trabalho junto ao cliente psicótico.

Vários benefícios foram citados pelos clientes durante a entrevista. O mais citado foi o melhor entendimento do que é a doença mental.

Antes en dizia pra todo mundo que era esquizofrênica, mas não sabia o que era essa doença, se tinha cura. Até que no grupo, um dia, eu perguntei o que era esquirofrenia e vocês me explicaram de uma forma que eu nunca mais esqueci $(e 2)$.

O grupo me fez aceitar que a minha doença não tem cura, mas que posso tratar dela sem problemas, sem me internar. Minha mãe não deixava eu falar pra ninguém que era esquizofrênico, mas quando me ensinaram no grupo o que é a doença, que é quimica na cabeça, eu expliquei pra ela e ficou mais fácil o tratamento (e5).

Nesses relatos observa-se o mito quanto à palavra esquizofrenia. A falta de informação do próprio cliente e de seus familiares provoca conflitos que interferem na maneira do cliente lidar com a sociedade. 
Da mesma forma, os clientes falam da cura de sua doença, da cronificação que vêem nos outros, e no grupo sempre se fala a respeito de ser a doença psiquiátrica curável, ou não. Sabemos que em determinadas situações pouco pode ser alterado no quadro clínico do cliente. Nessas situações trabalhamos a angústia do grupo, procurando alterar a dinâmica da reação do ambiente ao cliente. Isso por si só pode representar uma alteração significativa.

Durante os primeiros grupos, entre os temas abordados sempre estava incluída a medicação, seus pontos positivos e negativos, com o decorrer da atividade, observamos que sempre que entrava no grupo um novo membro, os clientes mais antigos discorriam sobre a medicação valorizando sua utilização para um melhor tratamento. Vejamos alguns relatos:

[...] eu trouxe ele para participar do grupo, porque agora vai tomar o NAP. Gostaria que vocês me deixassem explicar pra ele o que é a medicação (e3).

Eu faço uso de NAP porque vejo estrelinhas. Com a medicação passa esse efeito (e7).

Sempre ouvi vozes. Quando tomo a injeção de NAP as vozes somem, mas depois de 15 dias comecam a chamar pelo meu nome, ai já sei que está na hora de tomar de novo(e1).

Sempre tive muito medo de dizer que ouvia vozes e ninguém acreditar (e8).

Vim tomar o NAP porque minha esposa está internada aqui. Ela bebeu demais e deu três facadas na esposa de meu filho. Eu fiquei nervoso e comecei a ver estrelinhas (e7).

A partir do momento em que disponibilizamos ao cliente tempo e atenção, tornam-se maiores e melhores as condições de reabilitação do mesmo que, acreditando em suas possibilidades e potencialidades, discute com o técnico sua situação procurando soluções para seus questionamentos. Isso faz com que ele sinta-se bem, com condições de expressar-se e auxiliar os outros integrantes do grupo.

Diante de uma demanda que venha sob forma de um pedido de resposta ou solução imediata, atribuindo ao "doutor" o saber e o poder de curar, devese procurar responder de modo a convidar o sujeito a dirigir sua atenção para sua implicação naquilo de que se queixa e convidá-lo a se interessar pela dimensão subjetiva daquilo que o acomete ${ }^{1}$.

A partir desse entendimento estruturamos o grupo com enfoque educativo e de escuta, visando acompanhar o cliente quanto ao uso prolongado de psicofármacos, ajudá-lo a melhor compreender a própria doença e a entender que existem formas complementares de lidar com ela que, associadas aos medica- mentos, podem propiciar melhor qualidade de vida e autonomia.

\section{$O$ resgate da auto-estima}

O reconhecimento e valorização do ser é uma das peças fundamentais para a sobrevivência do indivíduo dentro do grupo. Todos nós precisamos nos sentir úteis de alguma forma à sociedade na qual estamos inseridos. Se este fato não ocorre, passamos a ser parte destacada e à margem do referido grupo.

Através de algumas respostas obtidas, observamos como o cliente psiquiátrico sente-se incapaz de pertencer ao mundo "sadio":

[...] como sou doente não vou às festas da igreja com minha mãe, vou só nos cultos. Nas festas eu posso dar alguma alteração, né?(e3).

Quando me olho no espelho eu mesma percebo que sou diferente, esses remédios, se eu me acho diferente imagina os outros (e6).

A gente é bonita quando tem saúde, ficou doente aí fica feia de vez (e3).

O grupo ajuda a entender os problemas, a resgatar a auto-estima $[\ldots]$ (e2).

Ao oferecermos um espaço para expressão de seus pensamentos, o cliente torna-se mais confiante diante de si e diante dos outros, pois percebe que é capaz de realizar determinadas coisas que antes julgava impossível. Essa abertura de possibilidades faz com que sua auto-estima se eleve e ele se permita atuar de modo positivo no seu tratamento.

Um ser falante que habita a linguagem e por ela é habitado, sofre seus efeitos. Nesta perspectiva, o sujeito é um suposto intérprete e construtor de uma realidade que inclui ele próprio e, por ser falante, experimenta a impossibilidade de tudo dizer e encontrar respostas além das palavras. Quando nos colocamos a escutar aquele que nos procura, convocamos o sujeito a falar daquilo que não pode ser dito?:

[...] aqui no grupo eu consigo falar, na consulta, muitas vezes fica difícil contar alguma coisa (e1).

Falar, nem sempre constitui uma atividade simples, diante dos clientes com dificuldade de usar a palavra durante o grupo, a equipe lança mão de medidas terapêuticas como encorajá-lo a reconhecer e expressar seus sentimentos. O profissional pode ajudar o cliente a lidar com o que em determinado momento é um desafio específico, muitas vezes, apenas o partilhar de um sentimento reduz sua ansiedade, levando-o a reavaliar a situação e a sua reação a ela. 
É importante ressaltar que o cliente precisa ser responsabilizado pelo seu tratamento, para que possa agir de modo a colaborar com a sua evolução, e isso só poderá ser feito se houver acontecido um engajamento anterior do mesmo, que só ocorrerá se sua auto-estima estiver em alta, permitindo a ele se ver como um ser capaz e fundamental no seu processo de reabilitação.

Ratificando nossa posição a cerca da responsabilização do sujeito nesse processo, "a orientação adotada em nossa prática articula a noção de sujeito de direito e sujeito da fala, adotando a noção de responsabilidade como um critério operativo importante na implicação do sujeito na escolha e condução de tudo que lhe diz respeito, inclusive no tratamento" 11:55.

Os clientes referem ser o momento de comemoração dos aniversários do mês fundamental para a elevação da auto estima de quem é homenageado, vejamos os relatos:

[...]quando ganbei presentes de aniversário me senti querida, me senti normal [...] (e7).

Me sinto bem de poder dar lembrancinhas no aniversário de um amigo. As festinhas no Grupo são ótimas para levantar o astral (e6).

Lá em casa minha mão fer. um bolinho [...] mas, estava ansioso pela nossa comemoração, mesmo fora do dia (e4).

Quando um cliente psicótico se dispõe a estabelecer trocas afetivas já se percebe uma mudança significativa em sua auto-estima para melhor, o empenho em elaborar, escolher e comprar um presente para o outro é de extrema valia para o tratamento porque envolve muito esforço do cliente para realizá-las.

\section{Comorbidades e efeitos colaterais}

Um outro problema abordado nos grupos é a comorbidade da doença mental com o alcoolismo. É comum essa questão surgir no grupo, pois o uso de bebida alcoólica é tido como uma prática social na nossa cultura.

Como ponto negativo no tratamento, nos deparamos com a utilização de bebidas alcoólicas concomitantes ao uso de medicação. Para o grupo se tornou mais um tema de esclarecimento de fácil entendimento para o cliente.

Diante dos relatos, pode-se observar que o grupo entra como um instrumento para evitar a associação do álcool com o psicofármaco, uma vez que não estamos lidando com clientes dependentes de álcool, se torna simples uma conscientização quanto aos malefícios da bebida.

Parei de tomar remédio e usar bebida depois que passei a freqüentar o grupo (e6).

É muito bom você ter parado de beber. Porque bebida e medicação não combinam (e4).

Meu pai é alcoólatra e fica transtornado com um tiquinho de bebida. Gostaria muito que ele viesse nesse grupo, mas ele diz que não vem. Isso me deixa triste porque en parei de beber devido ao grupo, e de repente ele se viesse [...] (e5).

Outros pontos negativos no tratamento muito citado nos grupos são os efeitos colaterais da medicação neuroléptica, nesse caso o NAP. Os clientes se sentem desmotivados ao tratamento devido aos efeitos indesejáveis que ocorrem com o uso da medicação. Vejamos alguns relatos:

[...] eu paro de tomar a medicação porque às vežes o remédio me deixa paradão, eu quero um tratamento mais natural, sem efeitos fora da cabeça (e8).

Fui cortado do clube, onde fazia judô, quando souberam que tomava remédio psiquiátrico, outra vez, não pude doar sangue pelo mesmo motivo (e5).

Eu queria muito dirigir, mas não posso por causa dos efeitos da medicação (e1).

A medicação atrapalha o homem (e8).

O comprimido não pode curar, Deus é quem pode. Eu nunca tive paz, e não é pelo remédio que vou alcançá-la (e4).

Fico tremendo, com fala arrastada, ando diferente, quem vai querer namorar um cara assim? (eØ).

Nesses casos a equipe procura levar os clientes ao entendimento dos benefícios trazidos com o uso da medicação, principalmente na redução dos sintomas psicóticos que se somam à dificuldade de construção de vínculos com o mundo externo. Dessa forma, comparando custos e benefícios do uso da medicação, o grupo chega a suas próprias conclusões quanto ao que vale mais a pena:

[...]é melhor ter esses efeitos e ficar em casa, do que não tomar o remédio e ficar internada (e2).

Eu funciono melhor com a medicação. Prefiro ter efeitos colaterais, mas conseguir viver minha vidinha (e7).

Não é só por causa dos efeitos da medicação que ele não pode dirigir. Sem tomar a medicação também não vai conseguir por causa da doença (e8).

Diante das observações feitas no grupo quanto 
à medicação e seus efeitos, não se trata de responsabilizá-la exclusivamente pelo sucesso do tratamento. Como antes já citado, a medicação pode ser usada como mais um dispositivo junto ao tratamento do cliente ambulatorial, pois "na rede como um todo o ambulatório fracassara enquanto estratégia de alternativa ao asilo, por ter se constituído contrariamente às suas intenções originais, em um serviço exclusivamente medicalizado e medicalizante, no limite indutor da farmacodependência e da cronificação" 1:81.

\section{Antes e depois do grupo do NAP: uma con- quista individual}

Como uma questão fundamental desse estudo, temos às modificações reais ocorridas na vida dos sujeitos devido à influência do grupo do NAP. Esta nova forma de assistência contempla ações diferenciadas que facilitam o estabelecimento de contatos interpessoais, o que para o psicótico constitui uma dificuldade. "Para aumentar o grau de adesão desses clientes e a continuidade do tratamento, elementos essenciais para reduzir o prejuízo e a incapacidade provocadas pela psicose é necessário estabelecer referências fixas" 8:1477.

Dentro desse contexto, pudemos verificar, nas afirmativas dos clientes, que estas modificações no atendimento ambulatorial foram fatores determinantes da qualificação da assistência prestada, uma vez que o grupo passou a representar um local fixo de referência: ajuda (e1).

[...] depois que passei a vir no grupo, ficou mais fácil pedir

Trabalho mais calma durante a semana porque sei que se acontecer algum problema, vai ter a reunião para eu falar (e3).

Vocês são mais do que doutores, são amigos com quem a gente pode contar. Sem falar que todos os pacientes que freqüentam o grupo do NAP tornaram-se meus amigos(e8).

Propomos entendermos o "desmedicalizar" como o ato de "romper com o circuito segundo o qual a um problema trazido pelo cliente, o profissional responderá com uma 'resposta-remédio', seja ela um remédio um diagnóstico, um encaminhamento precipitado ou mesmo uma interpretação"1:89.

Sendo assim, mesmo lidando com pacientes em uso de medicação por tempo indeterminado, faz-se necessário proporcionar ao cliente uma observação mais atenta dos seus sintomas, para que sua atitude perante eles não seja uma atitude passiva, esperando pelo aumento da dose de medicamento.
A partir das modificações estabelecidas na terapêutica ambulatorial, conseguimos direcionar o atendimento ao cliente psicótico para o seguinte entendimento: a medicação é parte do tratamento, que é de responsabilidade de cada cliente, que poderá contar com a ajuda dos técnicos do grupo, assim como com seu médico assistente.

\section{CONSIDERAÇÕES FINAIS}

Através do desenvolvimento desse estudo, podemos observar os efeitos positivos da criação do grupo do NAP. Além disso, observamos que a responsabilização do paciente pelo seu tratamento surte o efeito, anteriormente desconhecido ou subestimado, da conscientização do indivíduo a cerca das suas possibilidades e implicações reais no seu processo terapêutico.

É importante termos a noção de que, para que sejam percebidas modificações efetivas, o trabalho a ser desenvolvido é longo e requer investimento dos profissionais envolvidos, pois não devemos deixar a impressão que o mesmo é uma tarefa simples. Os problemas são vários e estamos continuamente nos confrontando com eles. A qualidade do trabalho desenvolvido depende de muitas variáveis que não apenas a modalidade de atendimento oferecida. Desta forma, nenhuma garantia temos que o grupo do NAP continuará trazendo tais conseqüências observadas no decorrer deste estudo. Por isso, é imprescindível o desenvolvimento de um trabalho contínuo, de competência, que possibilite uma nova atenção ao cliente psicótico, como uma alternativa de resolução pautada não em modelos, mas em questões estudadas a partir da demanda assistencial da clientela.

Porém, para que o processo de implantação se complete, é necessário contar com a adesão e compromisso dos profissionais que atuam na instituição. A implantação de um programa de garantia e avaliação sistemática da qualidade pode ser o instrumento que faltava para melhorar a qualidade dos serviços prestados no ambulatório. Os programas de avaliação da qualidade encorajam ao risco, às mudanças, ao aprimoramento e ao trabalho em equipe, o que facilita o diálogo, o entendimento e o conhecimento dos processos que cruzam as fronteiras dos setores de uma instituição. Isto é fundamental para introdução de mudanças que visam melhoria da qualidade.

Este estudo traz uma reflexão acerca da necessidade de encontrar novas alternativas para o atendi- 
mento psiquiátrico ambulatorial, o que irá contribuir para um melhor atendimento, que muitas vezes está resumido em consultas, medicação e internação, impedindo o cliente de investir em uma vida melhor, apesar da sua doença e das limitações que ela impõe, ficando sempre na condição de vítima do tratamento, que muitas vezes é insuficiente para suas necessidades. Sendo assim, a ação de profissionais interessados em oferecer ao cliente psiquiátrico melhores condições de vida a partir de novas propostas terapêuticas pode gerar melhores resultados para os clientes, além de promover o crescimento profissional para a equipe envolvida neste processo.

Este projeto não termina com o fim do curso de residência. Ele continua dentro da instituição realizado por técnicos permanentes e aberto aos futuros enfermeiros residentes, funcionando como mais um dispositivo de ensino e treinamento para a enfermagem em ambulatório psiquiátrico.

\section{REFERÊNCIAS}

1 Tenório F. A importância estratégica dos dispositivos de recepção. Cad IPUB 2000; 6(17): 7-14.

2 Levicovitz S. Grupos de recepção: uma introdução ao tema.
Cad IPUB 2000; 6(17): 21-9.

3 Pitta A. Reabilitação psicossocial no Brasil. Rio de Janeiro: HUCITEC; 1996.

4 Tavares M. O tear das cinzas [dissertação]. Rio de Janeiro (RJ): IPUB/UFRJ; 1992.

5 Rúdio EV. Introdução ao projeto de pesquisa científica. Petrópolis: Vozes; 1986.

6 Conselho Nacional de Saúde (BR). Resolução 196/96 de 10 de outubro. Dispõe sobre diretirzes e normas regulamentares de pesquisa envolvendo seres humanos. Brasília:O Conselho;1996.

7 Rivière EP. O processo grupal. São Paulo: Martins Fontes; 1983.

8 Achatz MH, D’Andrea FF. Psicoterapia de grupo com depressivos. J Bras Psiquiatr.1997; 36(2):101.

9 Rotzsch JMP. Qualidade em saúde mental. A RIPP - um modelo e sua avaliação [dissertação]. Rio de Janeiro (RJ): IPUB/UFRJ; 1997.

10 Corbisier C. A escuta da diferença na Emergência Psiquiátrica. In: Bezerra Junior B, Amarante, P, organizadores. Psiquiatria sem hospício. Rio de Janeiro: Relume-Dumará; 1992. p.172-84.

11 Maron G. Grupos de recepção: interrogando (n)os grupos. Cad IPUB 2000; 6(17): 46-58. 